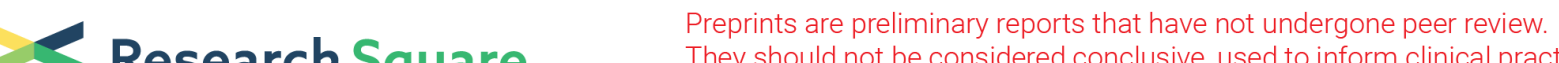 Research Square They should not be considered conclusive, used to inform clinical practice, or referenced by the media as validated information.
}

\section{"Enhancement of Vincristine Under In Vitro Culture of Catharanthus Roseus Supplemented With A/ternaria Sesami Endophytic Fungal Extract As Biotic Elicitor"}

\section{Kanchan Birat}

Department of Pharmacognosy \& Phytochemistry

\section{Tariq Omar Siddiqi}

Department of Botany, School of Chemical and Life Sciences

\section{Showkat Rasool Mir}

School of Pharmaceutical Education \& Research

\section{Junaid Aslan}

Department of Pharmacognosy \& Phytochemistry

\section{Rakhi Bansal}

Department of Pharmacognosy \& Phytochemistry

\section{Wasim Khan}

Department of Pharmacognosy \& Phytochemistry

Bibhu Prasad Panda ( $\nabla$ bppanda@jamiahamdard.ac.in )

Department of Pharmacognosy \& Phytochemistry https://orcid.org/0000-0001-5110-2945

\section{Research Article}

Keywords: Vindoline, Vincristine, Catharanthus roseus, Alternaria sesami, Endophyte

Posted Date: July 12th, 2021

DOI: https://doi.org/10.21203/rs.3.rs-308452/v1

License: (c) (i) This work is licensed under a Creative Commons Attribution 4.0 International License. Read Full License 


\section{Abstract}

Vincristine, one of the major vinca alkaloid of Catharanthus roseus(L.) G. Don. (Apocynaceae) was enhanced under in vitro culture of C.roseus using fungal extract of an endophyte Alternaria sesami isolated from the surface-sterilized root cuttings of $C$.roseus. Vindoline, a precursor molecule of Vincristine was detected for the first time from the fungal endophyte A.sesami which was used as biotic elicitor to enhance Vincristine content in the C.roseus callus.It was identified using high performance liquid chromatography and mass spectroscopy techniques by matching retention time and mass data with reference molecule. Supplementing heat sterilized $A$. sesami endophytic fungal culture extract into callus culture medium of $C$. roseus enhanced the Vincristine content in $C$. roseus callus by $21.717 \%$ after 105 day culture.

\section{Introduction}

Catharanthus roseus (L.) G. Don. (Apocynaceae), known commonly as Madagascar periwinkle or rosy periwinkle, has been a centre of attraction for Vinca alkaloids. Dimeric Vinca alkaloids (vinblastine and vincristine) are anticancer drugs that have been originally extracted from the plant. These indole alkaloids are highly potent anticancer drugs and find application in various types of cancers. Their biological properties rely on binding to tubulin protein and inhibit microtubule formation and mitotic spindle dynamics thus inhibiting mitosis process. ${ }^{[23]}$ Further, Vinca alkaloids act as angiogenesis inhibitor thus disrupting the intracellular transport and blood flow to tumor. ${ }^{[2]}$ Vindoline, a monomeric Vinca alkaloid constitutes the lower half of dimeric Vinca alkaloid vinblastine. ${ }^{[13]}$ It serves as natural precursor for biosynthesis of vinblastine and vincristine along with catharanthine. Vindoline also acts as synthetic precursor for semi synthetic analogue of Vinca alkaloids such as vindesine (Eldesine $\left.{ }^{\circledR}\right)$, vinorelbine (Navelbine ${ }^{\circledR}$ ) and vinflunine (Javlor $\left.{ }^{\circledR}\right)$. These semi synthetic molecules exhibit superior efficacy in the treatment of breast, bladder and lung cancer. ${ }^{[3]}$

Due to medicinal and pharmaceutical importance and low abundance of natural Vinca alkaloids such as vincristine and vinblastine, $C$. roseus is the most extensively studied medicinal plant for bioactive secondary metabolites. Advanced strategies over conventional breeding methods for the production of therapeutically important alkaloids have been carried outusing in vitro culture methods like callus culture, cell suspension, hairy root, etc. ${ }^{[7,14]}$ Although, semi synthetic analogue of Vinca alkaloids (vindesine, vinorelbine and vinflunine) are superior to natural Vinca alkaloids (vinblastine and vincristine) but their clinical supply depends on availability of their precursor molecules i.e. monomeric natural Vinca alkaloids (vindoline and catharanthine). ${ }^{[11]}$ Therefore, there is need to explore other sources (non plant) for uninterrupted supply of precursor molecules (monomeric Vinca alkaloids such as vindoline) and enhancement of natural vinca alkaloids in plant.

Fungal endophytes are well known as a rich resource of functional molecules and have been reported to produce a plethora of bioactive compounds inside and outside their host plant. Therefore, endophytic fungi are currently explored as alternative source for plant bioactive compounds. Some of the endophytic 
fungi are reported to produce taxol, podophyllotoxin, deoxypodophyllotoxin, camptothecin, hypericin, silybin A and B, etc. ${ }^{[18,19,20,21,24]}$

In the year 1998, Guo et al first reported Alternaria sp. (a fungal endophyte) producing vinblastine obtained from $C$. roseus. ${ }^{[8]}$ In the year 2004, Xianzhi et al found an unidentified endophytic fungus from the leaves of $C$. roseus capable of producing vincristine. ${ }^{[25]}$ These results show that endophytic fungi existing in $C$. roseus could be a potential source for production of vindoline (the precursor molecules for biosynthesis of dimeric Vinca alkaloids).

In this work, we have reported for the first time the production of a monomeric natural Vinca alkaloid, vindoline from a fungal endophyte, isolated from Catharanthus roseus and enhancement of vincristine content in $C$. roseus callus by treating with sterilized cellular extract of endophytic fungus producing vindoline. The fungus was identified as Alternaria sesami (Pleosporaceae) using genomic techniques.

\section{Materials And Methods}

Isolation, maintenance and Fermentation of the Fungal Endophyte: A young and healthy plant material of Catharanthus roseus (L.) G. Don (EC 120837) was obtained from herbal garden of Jamia Hamdard University, New Delhi, India. The leaves, stem and root of the plant were cut in to small pieces (approximately $2 \mathrm{~mm}$ size) with the help of a surgical blade, and washed in reverse osmosis water using cetrimide. Afterwards, the plant segments were surface sterilized (using optimised method) by adding plant material in $70 \%$ ethanol for 1 minute, rinsed twice with autoclaved water, and then the plant material was added to $0.1 \%$ mercuric chloride for 90 seconds, finally washed thrice with sterile water. The effectiveness of surface sterilization was determined by observing no bacterial growth in the rinsed water on potato dextrose agar (PDA) media after 7 days of incubation at $28^{\circ} \mathrm{C}$. The segments were transferred onto petri plates containing PDA media (Himedia, Mumbai, India) supplemented with antibiotic mixture of streptomycin sulphate $250 \mathrm{mg} / \mathrm{L}$ and penicillin G $250 \mathrm{mg} / \mathrm{L}$ in order to grow endophytic fungus without any contamination. Plates were sealed with parafilm and incubated at $28^{\circ} \mathrm{C}$ until the fungal colonies started oozing out of the explants.All of the isolated endophytic fungal cultures were maintained in PDA slant and sub-cultured in every 30 day interval. Isolated endophytes were cultured in liquid medium $(20 \mathrm{~g}$ dextrose, $1 \mathrm{~g}$ yeast extract, $3 \mathrm{~g}$ potassium dihydrogen sulphate, $1.5 \mathrm{~g}$ magnesium sulphate. $7 \mathrm{H}_{2} \mathrm{O}, \mathrm{pH} 6.0$ ) in $250 \mathrm{~mL}$ Erlenmeyer flasks at $28^{\circ} \mathrm{C}, 110 \mathrm{rpm}$ in a shaker incubator. After 6 days, the culture (fungal biomass) were separated and analysed for monomeric/dimeric Vinca alkaloids by qualitative analysis using high performance liquid chromatography (HPLC) and mass spectrometry separately.

Extraction \& analysis of vinca alkaloids: Various endophytes isolated from the explants were analysed for the presence of the secondary metabolites through qualitative analysis mode using high performance liquid chromatography (HPLC) technique. The fungal biomass was obtained by filtration process using Whatman No 1 filter paper and dried at $50^{\circ} \mathrm{C}$ for $4 \mathrm{hr}$ in a hot air oven. To the dried fungal biomass, methanol was added ( $25 \mathrm{ml}$ per $5 \mathrm{~g}$ of dried biomass) and sonicated (Pulse-30Khz, Gap-10 seconds, amplitude-100\%) for 10 min using probe sonicator (VCX 130, Vibra Cell, Sonics, USA). After the sonication 
process, supernatant was collected by centrifugation ( $1537 \mathrm{~g}$ for $5 \mathrm{~min}$ ), evaporated to dryness in a vacuum evaporator at $60^{\circ} \mathrm{C}$. For HPLC-UV analysis, the dried extract was dissolved in equal volume of methanol and filtered through $0.45 \mu \mathrm{m}$ membrane. Elution was carried out by the mobile phase consisting of methanol and water with $0.1 \%$ triethylamine at a flow rate of $1 \mathrm{ml} / \mathrm{min}$ under gradient mode ( $55 \% \mathrm{v} / \mathrm{v}$ methanol at $0 \mathrm{~min}, 65 \% \mathrm{v} / \mathrm{v}$ methanol at $5 \mathrm{~min}, 70 \% \mathrm{v} / \mathrm{v}$ methanol at $15 \mathrm{~min}, 80 \% \mathrm{v} / \mathrm{v}$ methanol at $18 \mathrm{~min}, 90 \% \mathrm{v} / \mathrm{v}$ methanol at $35 \mathrm{~min}, 55 \% \mathrm{v} / \mathrm{v}$ methanol at $40 \mathrm{~min}) .{ }^{[10,27]}$ Detection was carried at $260 \mathrm{~nm}$. The mass analysis was carried out on UPLC MS/MS analyser of "WATERS" and data were acquired using MassLynx4.1 software. Source temperature was set at $80^{\circ} \mathrm{C}$ and the gas flow at $500 \mathrm{l} / \mathrm{hr}$.

Identification of the endophytic fungal strain: The vindoline producing endophytic fungus was identified and characterized by using molecular biology techniques as per the manufacturer protocol (Bhat Biotech, Bangalore, India). Fungal genomic DNA was extracted from fungus using genomic DNA extraction kit from fresh culture of MPBL 105 (desired endophytic fungus). Amplification of the nuclear internal transcribed spacers (ITS) region was performed using the universal primers ITS1 (5'TCCGTAGGTGAACCTGCGG-3') and ITS4 (5'-TCCTCCGCTTATTGATATGC-3'). The amplification was carried out in a Master cycler ${ }^{\circledR}$ Thermocycler (Eppendorf, Germany) using the following program. Polymerase chain reaction (PCR) was performed with initial denaturation of $94^{\circ} \mathrm{C}$ for 2 minutes followed by 40 cycles of denaturation at $94^{\circ} \mathrm{C}$ for $1 \mathrm{~min}$, annealing at $55.5^{\circ} \mathrm{C}$ for $1 \mathrm{~min}$ and extension at $72^{\circ} \mathrm{C}$ for $30 \mathrm{sec}$. Final extension was carried out at $72^{\circ} \mathrm{C}$ for $10 \mathrm{~min}$. Amplified PCR products were separated in $1 \%$ agarose gel containing ethidium bromide in $0.5 \mu \mathrm{g} / \mathrm{ml}$ concentration (for detection of bands under UV) in Tris-Borate -EDTA (TBE) buffer. The purified PCR product was used for sequencing. Sequencing was carried by automated DNA sequence machine - 3037x/DNA analyzer from Applied Biosystems using BigDye ${ }^{\circledR}$ Terminator v3.1 cycle sequencing Kit (Applied Biosystems). Sequence data were aligned and dendrograms were generated using sequence analysis software version 5.2 from Applied Biosystems. Sequences were compared to the non-redundant NCBI database by using BLASTN, with the default settings used to find the most similar sequence and were sorted by the E score. A representative sequence of 10 most similar neighbours was aligned using CLUSTAL W2 for multiple alignments with the default settings. The multiple-alignment file was then used to create phylogram using Molecular Evolutionary Genetic Analysis (MEGA 5) software. On the basis of the results of the BLAST search, the isolated endophytic fungal strain MPBL 105 was identified as Alternaria sesami (Pleosporaceae).

Establishment of $C$. roseas callus culture: Healthy and immature leaves of Catharanthus roseus (L.) G.Don.were collected from the herbal garden, Jamia Hamdard University, New Delhi and used as explants for callus culture. The explants were washed in running reverse osmosis water for 10 minutes using cetrimide and were subjected to surface sterilization using $70 \%$ ethanol and $0.1 \%$ mercuric chloride.For $C$. roseas callus culture MS (Murashige and Skoog) media was used as basal media with $3 \%$ sugar, $1.1 \%$ agar, $0.01 \%$ myoinositol and combination of different growth hormones [naphthalene acetic acid (NAA), indole acetic acid (IAA), kinetin, 2,4-dichlorophenoxyacetic acid (2,4-D), 6-benzyladenine (6-BA)]. ${ }^{[15]}$ The incubation temperature was $25^{\circ} \mathrm{C}$ and light intensity of 1600 lux with $16 \mathrm{hr}$ photoperiods per day. The callus was sub-cultured after every 21 days and grown and maintained for 90 days. After 90 days, $C$. 
roseas callus was treated with methanolic or aqueous extract of fungal endophyte (A. sesami) at a concentration of $25 \mu \mathrm{l} / \mathrm{g}$ of media, $50 \mu \mathrm{l} / \mathrm{g}$ of media, and $100 \mu \mathrm{l} / \mathrm{g}$ of media and grown for another 15 days under same culture condition. After a total 105 days of growth, each callus was collected and fresh weight was noted. Further the callus was dried at $60^{\circ} \mathrm{C}$. The drying was carried out up to the constant weight of the callus. To the dried callus, methanol was added ( $5 \% \mathrm{v} / \mathrm{w})$ and sonicated (Pulse-30Khz, Gap10 seconds, amplitude-100\%) for 15 min using probe sonicator (VCX 130,Vibra Cell, Sonics, USA). After the sonication, biomasswas centrifuged for $5 \mathrm{~min}$ at $1537 \mathrm{~g}$ and the supernatant was collected and evaporated to dryness in a vacuum evaporator at $60^{\circ} \mathrm{C}$. The dried extract was dissolved in equal volume of methanol and filtered through $0.45 \mu \mathrm{m}$ membrane and analysed by HPLC -UV using same procedures as described in above section.

\section{Results}

Isolation, identification and characterization of isolated endophytic fungus: From a variety of endophytic fungi isolated from C.roseus only one fungus (Fig. 1) was showing positive result for the presence of vindoline in fungal extract. The presence of vindoline in the fungal extract was evident by the HPLC and mass spectrometry data. RT recorded for HPLC peak of vindoline standard was recorded to be 18.465 (Supp Fig S4) and that of vindoline in fungal extract was recorded to be 18.392 at 260nm (Fig. 2). Regression via area for vindoline was found to be 0.997 (Supp. Fig S5) and for vincristine it was 0.983 (Supp. Fig S6). Mass spectrum of vindoline in fungal extract detected the molecular weight of vindoline to be $456.3634 \mathrm{~g} / \mathrm{mol}$ (Fig. 3) which matched the mass spectrum of vindoline standard which was $456.5 \mathrm{~g} / \mathrm{mol}$ in the PubChem database. Hence the mass spectrum and HPLC results both confirm the presence of vindoline in the fungal extract.

The band for PCR product was recorded to be around 600bp (Fig. 4). The fungal strain was confirmed by sequence analysis (Supp Data S1) and formation of phylogenetic tree (Fig. 5). The evolutionary history inferred using the Neighbour-Joining method shows optimal tree with the sum of branch length = 0.00400000 (Next to the branches). The evolutionary distances were computed using the $p$-distance method and are in the units of the number of base differences per site. The analysis involved 11 nucleotide sequences. All positions containing gaps and missing data were eliminated. There were a total of 500 positions in the final dataset. Sequence analysis of the ITS region of rRNA gene showed that the Sample MPBL 103 is Alternaria sesami.

The quantitative analysis of fungal extracts showed that the isolated fungus Alternaria sesami produces vindoline in concentration of $1.47 \mu \mathrm{g} / \mathrm{g}$ of cell biomass but it is not found to be producing vincristine (Table 1). 
Table 1

Concentration of vindoline in fungal extract

\begin{tabular}{|llll|}
\hline $\begin{array}{l}\text { S. } \\
\text { No. }\end{array}$ & $\begin{array}{l}\text { Total cell } \\
\text { biomass of } \\
\text { fungus }(\mathbf{g})\end{array}$ & $\begin{array}{l}\text { Concentration of vindoline } \\
\text { produced by total cell biomass } \\
(\boldsymbol{\mu g})\end{array}$ & $\begin{array}{l}\text { Concentration of vindoline produced } \\
\text { per gram of cell biomass }(\boldsymbol{\mu g} / \mathrm{g})\end{array}$ \\
\hline 1. & 31.482 & $46.1557 \mu \mathrm{g}$ & $1.47 \mu \mathrm{g} / \mathrm{g}$ \\
\hline
\end{tabular}

Callus culture and hormone treatment: Callus initiation was optimized using different hormone combinations. Best hormonal combinations and their concentration for callus growth were observed (Supp Table S1 \& S2; Supp Fig S1 \& S2). With 7th hormone combination [2, 4-D + IAA + 6-BA] (Supp Fig. 1C) and 10th hormone combination [2,4-D + IAA + Kinetin + 6-BA] (Supp Fig S1 E) good callus growth was observed after 15 day. Therefore these hormone combinations were usedfor the optimum growth initiation and sub culturing. A healthy callus was observed using 7th hormone combination (Fig. 6a) and 10th hormone combnation (Fig. 6b). For callus development and good growth in 7th hormone combination (Fig. 7a) and 10th hormone combination (Fig. 7b), 1ppm (each) was considered suitable hormone concentration. The growth pattern and production of vindoline and vincristine was observed in untreated callus, callus treated with fungal water extract, and callus treated with fungal methanol extract with 7th hormone combinations (Table 2) and 10th hormone combinations (Table 3). 
Table 2

Treatmentof the callus of 7th hormone combination (2, 4-D + IAA + 6-BA).

\begin{tabular}{|c|c|c|c|c|c|c|c|}
\hline S.No & $\begin{array}{l}\text { Type of } \\
\text { callus }\end{array}$ & $\begin{array}{l}\text { Initial } \\
\text { fresh } \\
\text { weight } \\
\text { (g) }\end{array}$ & $\begin{array}{l}\text { Fresh } \\
\text { weight } \\
\text { after } 20 \\
\text { days }(\mathrm{g})\end{array}$ & $\begin{array}{l}\text { Initial } \\
\text { colour }\end{array}$ & $\begin{array}{l}\text { Colour } \\
\text { after } 20 \\
\text { days }\end{array}$ & $\begin{array}{l}\text { Concentration } \\
\text { of vindoline } \\
\text { ( } \mu \mathrm{g} / \mathrm{mg} \text { of } \mathrm{dry} \\
\text { callus) }\end{array}$ & $\begin{array}{l}\text { Concentration } \\
\text { of vincristine } \\
\text { ( } \mu \mathrm{g} / \mathrm{mg} \text { of } \mathrm{dry} \\
\text { callus) }\end{array}$ \\
\hline 1 & Untreated & 0.356 & 2.00 & $\begin{array}{l}\text { Yellowish } \\
\text { white }\end{array}$ & $\begin{array}{l}\text { Yellowish } \\
\text { white }\end{array}$ & 0.7894 & 5.765 \\
\hline \multicolumn{8}{|c|}{ Treated with fungal water extract } \\
\hline $2 a$ & $25 \mu \mathrm{l} / \mathrm{g}$ & 0.367 & 2.39 & $\begin{array}{l}\text { Yellowish } \\
\text { white }\end{array}$ & $\begin{array}{l}\text { Dark } \\
\text { yellow }\end{array}$ & 1.559 & -- \\
\hline $2 b$ & $50 \mu \mathrm{l} / \mathrm{g}$ & 0.400 & 2.17 & $\begin{array}{l}\text { Yellowish } \\
\text { white }\end{array}$ & $\begin{array}{l}\text { Dark } \\
\text { yellow }\end{array}$ & 2.495 & -- \\
\hline $2 c$ & $100 \mu \mathrm{l} / \mathrm{g}$ & 0.346 & 2.228 & $\begin{array}{l}\text { Yellowish } \\
\text { white }\end{array}$ & $\begin{array}{l}\text { Dark } \\
\text { yellow }\end{array}$ & 4.675 & -- \\
\hline \multicolumn{8}{|c|}{ Treated with fungal methanolic extract } \\
\hline $3 a$ & $25 \mu \mathrm{l} / \mathrm{g}$ & 0.398 & 2.188 & $\begin{array}{l}\text { Yellowish } \\
\text { white }\end{array}$ & $\begin{array}{l}\text { Dark } \\
\text { yellow }\end{array}$ & 7.867 & -- \\
\hline $3 b$ & $50 \mu \mathrm{l} / \mathrm{g}$ & 0.347 & 0.532 & $\begin{array}{l}\text { Yellowish } \\
\text { white }\end{array}$ & $\begin{array}{l}\text { Dark } \\
\text { yellow }\end{array}$ & 2.610 & -- \\
\hline $3 c$ & $100 \mu \mathrm{l} / \mathrm{g}$ & 0.410 & 0.733 & $\begin{array}{l}\text { Yellowish } \\
\text { white }\end{array}$ & $\begin{array}{l}\text { Dark } \\
\text { yellow }\end{array}$ & 1.739 & -- \\
\hline
\end{tabular}


Table 3

Treatmentof the callus of 10th hormone combination (2,4-D + IAA + Kinetin + 6-BA).

\begin{tabular}{|c|c|c|c|c|c|c|c|}
\hline S.No & $\begin{array}{l}\text { Type of } \\
\text { callus }\end{array}$ & $\begin{array}{l}\text { Initial } \\
\text { fresh } \\
\text { weight } \\
\text { (g) }\end{array}$ & $\begin{array}{l}\text { Fresh } \\
\text { weight } \\
\text { after } 20 \\
\text { days (g) }\end{array}$ & $\begin{array}{l}\text { Initial } \\
\text { colour }\end{array}$ & $\begin{array}{l}\text { Colour } \\
\text { after } 20 \\
\text { days }\end{array}$ & $\begin{array}{l}\text { Concentration } \\
\text { of vindoline } \\
\text { ( } \mu \mathrm{g} / \mathrm{mg} \text { of } \mathrm{dry} \\
\text { callus) }\end{array}$ & $\begin{array}{l}\text { Concentration } \\
\text { of vincristine } \\
\text { ( } \mu \mathrm{g} / \mathrm{mg} \text { of } \mathrm{dry} \\
\text { callus) }\end{array}$ \\
\hline 1 & untreated & 0.350 & 1.209 & $\begin{array}{l}\text { Yellowish } \\
\text { white }\end{array}$ & $\begin{array}{l}\text { Yellowish } \\
\text { white }\end{array}$ & 4.43 & -- \\
\hline \multicolumn{8}{|c|}{ Treated with fungal water extract } \\
\hline $2 a$ & $25 \mu \mathrm{l} / \mathrm{g}$ & 0.347 & 4.180 & $\begin{array}{l}\text { Yellowish } \\
\text { white }\end{array}$ & $\begin{array}{l}\text { Dark } \\
\text { yellow }\end{array}$ & 2.558 & 0.444 \\
\hline $2 b$ & $50 \mu \mathrm{l} / \mathrm{g}$ & 0.346 & 2.333 & $\begin{array}{l}\text { Yellowish } \\
\text { white }\end{array}$ & $\begin{array}{l}\text { Dark } \\
\text { yellow }\end{array}$ & 0.60 & - \\
\hline $2 c$ & $100 \mu \mathrm{l} / \mathrm{g}$ & 0.356 & 0.967 & $\begin{array}{l}\text { Yellowish } \\
\text { white }\end{array}$ & $\begin{array}{l}\text { Dark } \\
\text { yellow }\end{array}$ & 1.38 & - \\
\hline \multicolumn{8}{|c|}{ Treated with fungal methanolic extract } \\
\hline 3a & $25 \mu \mathrm{l} / \mathrm{g}$ & 2.188 & 1.100 & $\begin{array}{l}\text { Yellowish } \\
\text { white }\end{array}$ & $\begin{array}{l}\text { Dark } \\
\text { yellow }\end{array}$ & 4.77 & - - \\
\hline $3 b$ & $50 \mu \mathrm{l} / \mathrm{g}$ & 0.532 & 0.830 & $\begin{array}{l}\text { Yellowish } \\
\text { white }\end{array}$ & $\begin{array}{l}\text { Dark } \\
\text { yellow }\end{array}$ & 3.28 & 21.717 \\
\hline $3 c$ & $100 \mu \mathrm{l} / \mathrm{g}$ & 0.733 & 0.500 & $\begin{array}{l}\text { Yellowish } \\
\text { white }\end{array}$ & $\begin{array}{l}\text { Dark } \\
\text { yellow }\end{array}$ & 0.699 & 9.209 \\
\hline
\end{tabular}

After 90 days of callus growth in 7th hormone combination [2, 4-D + IAA + 6-BA] (1ppm each) and 10th hormone combination [2, 4-D + IAA + Kinetin + 6-BA] (1ppm each) good growth pattern was observed (Supp Table S3; Supp Fig S3A \& S3B).

In $7^{\text {th }}$ hormone combination the growth was more in the callus treated with water extract than the untreated callus. However, the growth was less in methanol extract treated callus. The change in colour from yellowish white to dark yellow was observed in all treated callus while no change in colour was observed in untreated callus. Concentration of vindoline was lowest in the untreated callus which was found to be $0.7894 \mu \mathrm{g} / \mathrm{mg}$ of dry callus and highest in callus treated with $25 \mu \mathrm{l} / \mathrm{g}$ of methanol extract which was $7.867 \mu \mathrm{g} / \mathrm{mg}$ of dry callus, however, vincristine was found present in a concentration of 5.765 $\mu \mathrm{g} / \mathrm{mg}$ of dry callus in untreated callus but absent in all the treated callus.

In $10^{\text {th }}$ hormone combination the growth of callus was more in the callus treated with water extract than the untreated callus. However, the growth was less in methanol extract treated callus. The change in colour was same in all treated callus i.e. from yellowish white to dark yellow while no change in colour was observed in untreated callus. Concentration of vindoline was found to be lowest in the water extract 
treated callus $(50 \mu \mathrm{l} / \mathrm{g})$ which was noted to be $0.60 \mu \mathrm{g} / \mathrm{mg}$ of dry callus. The concentration of vindoline was highest in methanol extract treated callus $(25 \mu \mathrm{l} / \mathrm{g})$ which was noted to be $4.77 \mu \mathrm{g} / \mathrm{mg}$ of dry callus. The concentration of vindoline decreases as the concentration of fungal methanol extract increases. Vincristine was produced in the treated callus and the highest conversion from vindoline to vincristine i.e. $3.28 \mu \mathrm{g} / \mathrm{mg}$ of dry callus to $21.717 \mu \mathrm{g} / \mathrm{mg}$ of dry callus, took place in the callus treated with $50 \mu \mathrm{l} / \mathrm{g}$ methanol extract.

The HPLC data for the callus cultures containing fungal water extract and fungal methanol extract showed the presence of vindoline and vincristine (Table 4).

Table 4

HPLC data for simultaneous analysis of vindoline and vincristine in untreated and treated callus

\begin{tabular}{|c|c|c|c|c|c|c|}
\hline S.No & Type of callus & $\begin{array}{l}\text { Hormone } \\
\text { combination }\end{array}$ & $\begin{array}{l}\text { Concentration } \\
\text { of fungal extract }\end{array}$ & $\begin{array}{l}\text { Compound } \\
\text { detected }\end{array}$ & $\begin{array}{l}\text { RT } \\
\text { (minutes) } \\
\text { at 260nm }\end{array}$ & Figure \\
\hline 1 & Untreated & 7 th & - & vindoline & 15.547 & $8(a)$ \\
\hline 2 & Untreated & 7 th & - & vincristine & 20.414 & $8(a)$ \\
\hline 3 & $\begin{array}{l}\text { Treated with } \\
\text { fungal methanol } \\
\text { extract }\end{array}$ & 7 th & $25 \mu \mathrm{l} / \mathrm{g}$ & vindoline & 15.173 & $8(b)$ \\
\hline 4 & $\begin{array}{l}\text { Treated with } \\
\text { fungal methanol } \\
\text { extract }\end{array}$ & 10th & $25 \mu \mathrm{l} / \mathrm{g}$ & vindoline & 15.173 & $8(c)$ \\
\hline 5 & $\begin{array}{l}\text { Treated with } \\
\text { fungal methanol } \\
\text { extract }\end{array}$ & 10th & $50 \mu \mathrm{l} / \mathrm{g}$ & vindoline & 15.436 & $8(d)$ \\
\hline 6 & $\begin{array}{l}\text { Treated with } \\
\text { fungal methanol } \\
\text { extract }\end{array}$ & 10th & $50 \mu \mathrm{l} / \mathrm{g}$ & vincristine & 19.123 & $8(d)$ \\
\hline
\end{tabular}

The standard plot data for vindoline and vincristine are presented in supplementary Table S4 \& S5.

\section{Discussion}

Vincristine and vinblastine are of great importance in cancer treatment and vindoline is a precursor molecule for their synthesis. Through various biosynthetic pathways and enzymes the coupling of monomeric alkaloids catharanthine and vindoline help in the production of these dimeric alkaloids. The product of the coupling reaction is $3^{\prime}, 4^{\prime}$-anhydrovinblastine which gets converted into vinblastine and further converts into vincristine (Supp Fig S7). These processes may speed up if there is an increased supply of monomeric precursor molecules like vindoline and catharanthine in the biosynthetic pathway. 
Elicitor-receptor interaction is an important step in the mechanism of elicitation to trigger a rapid array of biochemical responses in plants. ${ }^{[5]}$

The endophytes may benefit either by producing host secondary metabolites or by augmenting plant defenses against pathogens or pest invasions to effectively prevent the other invading pathogens. This can happen only if the endophyte is resistant to the metabolite and the metabolite is transported across the mycelial cell membrane and the cell wall into the intercellular spaces of plant tissue. ${ }^{[16]}$

Hormones are a necessity for induction of any callus. MS medium supplemented with 2,4dichlorophenoxyacetic acid (2,4-D) and 6-Benzylaminopurine (6-BA) mightgive $100 \%$ callus induction. ${ }^{[12]}$ The presence of kinetin in the 7th hormone combination in the media might have helped in the conversion process of vindoline to vincristine in the callus with the help of vindoline present in fungal methanol extract. ${ }^{[1]}$

Alternaria specie is found as endophyte in various medicinal plants such as Catharanthus roseus, Rauvolfia serpentine, Ziziphus jujube, Salvadora persica, etc. ${ }^{[4,6,17,22]}$ However it produces a variety of host specific products such as antimicrobial, anticancer and antioxidant compounds which are beneficial for medical industry.

Stress conditions may induce the production of secondary metabolite synthesis in plants. Abiotic and biotic elicitors are used for obtaining medicinally important bioactive secondary metaboilites from the plants in higher concentrations. ${ }^{[9]}$ Hence elicitation using Alterneria sesami fungal extracts in optimum concentration may be used as biotic elicitor for enhanced production of the anticancer bioactive metabolite vincristine under in vitro culture of C.roseus.

\section{Conclusion}

Catharanthus roseus is well known plant to have high medicinal value and is home to a variety of endophytic fungi. It produces secondary metabolites known to have anticancer properties. This study shows that Alternaria sesami fungal methanol extract can be used as a biotic elicitor for the large scale production of vincristine in the callus of C.roseus cultured in laboratory condition which might help in increment of the yield of the bioactive secondary metabolite vincristine with the help of vindoline produced in the fungal culture. As vincristine is used in various cancer treatments this method might reduce the high cost of such products and may prove to be revolutionary in medical industry. However further study may be required where in planta concentrations of vincristine may also be increased using A. sesami or any other vindoline producing fungal extract.

\section{Declarations}

\section{Declaration of interest statement}


Kanchan Birat, Tariq Omar Siddiqi, Showkat Rasool Mir, Junaid Aslan, Rakhi Bansal, Wasim Khan and Bibhu Prasad Panda declare that they have no conflict of interest.

\section{Supplementary data available}

The data available in attached supplementary file includes comparison of plant growth hormone combinations for good callus initiation, effect of hormone concentration on callus growth, callus growth in 90 day culture, HPLC data for vindoline standard, standard plot for vindoline detection, standard plot for vincristine detection, aligned sequence of isolated fungus Alternaria sesami and biosynthetic pathway for vincristine production with precursor molecule vindoline.

\section{Aknowledgements}

The first author is thankful to CSIR-UGC for providing scholarship for carrying out this work. The author also acknowledges the efforts of DST for providing financial assistance through (DST-Purse) when no other source of finances was observed. The author is grateful to School of Chemical and Life Science and the Central Instrumentation Facility (CIF), Jamia Hamdard, for providing research facilities.

\section{References}

1. Almagro L, Fernández-Pérez F,PedreñoMA (2015) Indole alkaloids from Catharanthus roseus: bioproduction and their effect on human health. Molecules20, 2973-3000.

2. Bates $D$,Eastman $A(2017)$ Microtubule destabilising agents: far more than just antimitotic anticancer drugs.Br J Clin Pharmacol 83(2) 255-268.

3. Brown I, Sangrithi-Wallace JN, Schofield AC, (2008) Anticancer therapeutics. Wiley- Blackwell, Chapter 6.

4. ElgorbanAM, BahkaliAH, Al-Farraj DA,Abdel-WahabMA (2019) Natural products of Alternaria sp., an endophytic fungus isolated from Salvadora persica from Saudi Arabia. Saudi Journal of Biological Sciences 26 (5) 1068-1077

5. El-Sayed M,VerpoorteR(2007) Catharanthus terpenoid indole alkaloids: biosynthesis and regulation. Phytochem Rev 6, 277-305

6. Ghosh R, BarmanS, Jgs P, MandalN (2018) Biological activities of alternaria sp. RL4 - a potent endophytic fungus associated with Rauvolfia serpentina L. Benth.Asian Journal of Pharmaceutical and Clinical Research11 (11) 178.

7. Goldhaber-PasillasGD,Mustafa NR, VerpoorteR, (2014) Jasmonic Acid Effect on the Fatty Acid and Terpenoid Indole Alkaloid Accumulation in Cell Suspension Cultures of Catharanthus roseus. Molecules 19:10242-10260.

8. Guo B, Li H, Zhang L (1998) Isolation of an fungus vinbrastine.Natural Sciences20(3) 214-215

9. Halder M, Sarkar S, Jha S(2019) Elicitation: A biotechnological tool for enhanced production of secondary metabolites in hairy root cultures. Engeneering in Life Sciences 880-895. 
10. Kumar A, Patil D, Rajamohanan PR, Ahmad A (2013) Isolation, Purification and Characterization of Vinblastine and Vincristine from Endophytic Fungus Fusarium oxysporum Isolated from Catharanthus roseusPLOS ONE 8 (9) e71805.

11. Lee CT, HuangYW, Yang CH, HuangKS(2015) Drug delivery systems and combination therapy by using vinca alkaloids. Curr Top Med Chem 15(15) 1491-1500.

12. LiuJ, FengH, MaY, ZhangL,Han H, HuangX (2018) Effects of different plant hormones on callus induction and plant regeneration of miniature roses(Rosa hybrida L.). Horticult Int J 2(4): 201-206

13. MisraN,LuthraR, Singh KL, KumarS(1999) Bioconversion of Ajmalicine to Serpentine in Catharanthus roseus Roots. Comprehensive Natural Products Chemistry25-59.

14. MorenoPRH,Heijden RVD, VerpoorteR(1995) Cell an tissue cultures of Catharanthus roseus: A literature survey. Plant Cell Tissue Organ Cult 42(1): 1-25

15. MurashigeT, SkoogF(1962) A Revised Medium for Rapid Growth and Bio Assays with Tobacco Tissue Cultures. Physiol. Plant 15, 473-497.

16. NaikS, ShaankerRU, Ravikanth G, DayanandanS(2019) How and why do endophytes produce plant secondary metabolites.Symbiosis 78, 193-201

17. OrfaliRS, Ebrahim W, El-ShafaeAM (2017)Secondary metabolites from Alternaria sp., a fungal endophyte isolated from the seeds of Ziziphus jujube. Chem Nat Compd., (53) 1031-1034.

18. PandeySS, SinghS, BabuCSV, ShankerK, SrivastavaNK, Shukla AK, KalraA, (2016) Fungal endophytes of Catharanthus roseus enhance vindoline content by modulating structural and regulatory genes related to terpenoid indole alkaloid biosynthesis. Scientific Reports 6.26583

19. PorterJ, Eyberger AL, RajiD, (2006) Endophyte Fungal Isolates from Podophyllum peltatum Produce Podophyllotoxin. Journal of Natural Products69. 1121-1124.

20. PuriSC, VermaV, AmnaT, Qazi GN, SpitellerM(2006) An endophytic fungus from Nothapodytes foetida that produces camptothecin. Journal of natural products68.

21. RaiN, KeshriPK, VermaA,KambleSC, MishraP, BarikS, Singh SK, GautamV(2021) Plant associated fungal endophytes as a source of natural bioactive compounds. Mycology (10)1080

22. SreekanthD, Kristin IM,BrettAN (2017) Endophytic fungi from Catharanthus roseus: A potential resource for the discovery of antimicrobial polyketides. Natural Products Chemistry and Research (5) 2.

23. StantonRA, GernertKM, Nettles JH, AnejaR(2011) Drugs That Target Dynamic Microtubules: A New Molecular Perspective. Med Res Rev31(3): 443-481.

24. UzmaF, MohanCD, HashemA, KonappaNM, RangappaS, KamathPV, SinghBP, MudiliV, GuptaVK, SiddaiahCN, ChowdappaS, Alqarawi AA,Abd_AllahEF., (2018) Endophytic Fungi-Alternative Sources of Cytotoxic Compounds: A Review.Front Pharmacol 9:309.

25. XianzhiY, LingqiZ, Bo G,ShipingG(2004) Priliminary study of a vincristine-producing endophytic fungus isolated from leaves of Catharanthus roseus. Europe PMC 35(1): 79-81. 
26. XiaoxuanZ, XinyiZ,Chao S, ShilinC(2014) Biosynthetic pathway of terpenoid indole alkaloids in Catharanthus roseus. Frontiers of medicine 8 (10) 1007/s11684-014-0350-2.

27. ZhouH, TaiY, Sun C, PanY(2005) Rapid identification of vinca alkaloids by direct-injection electrospray ionisation tandem mass spectrometry and confirmation by high-performance liquid chromatography-mass spectrometry. Phytochemical analysis 852

\section{Figures}

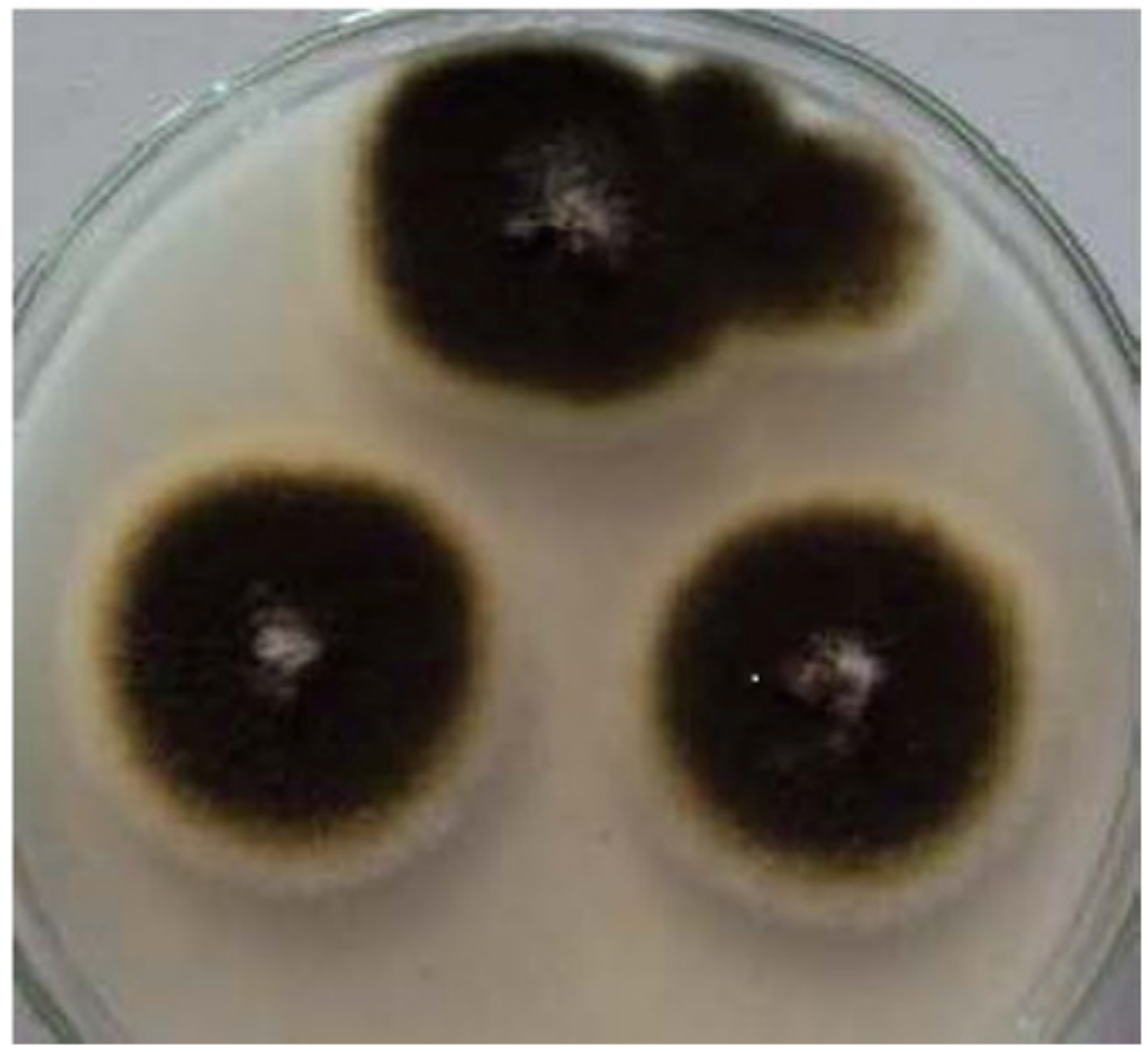

\section{Figure 1}

Isolated endophytic fungus Alternaria sesami oozing out of the C. roseus explant in PDA petri plate 


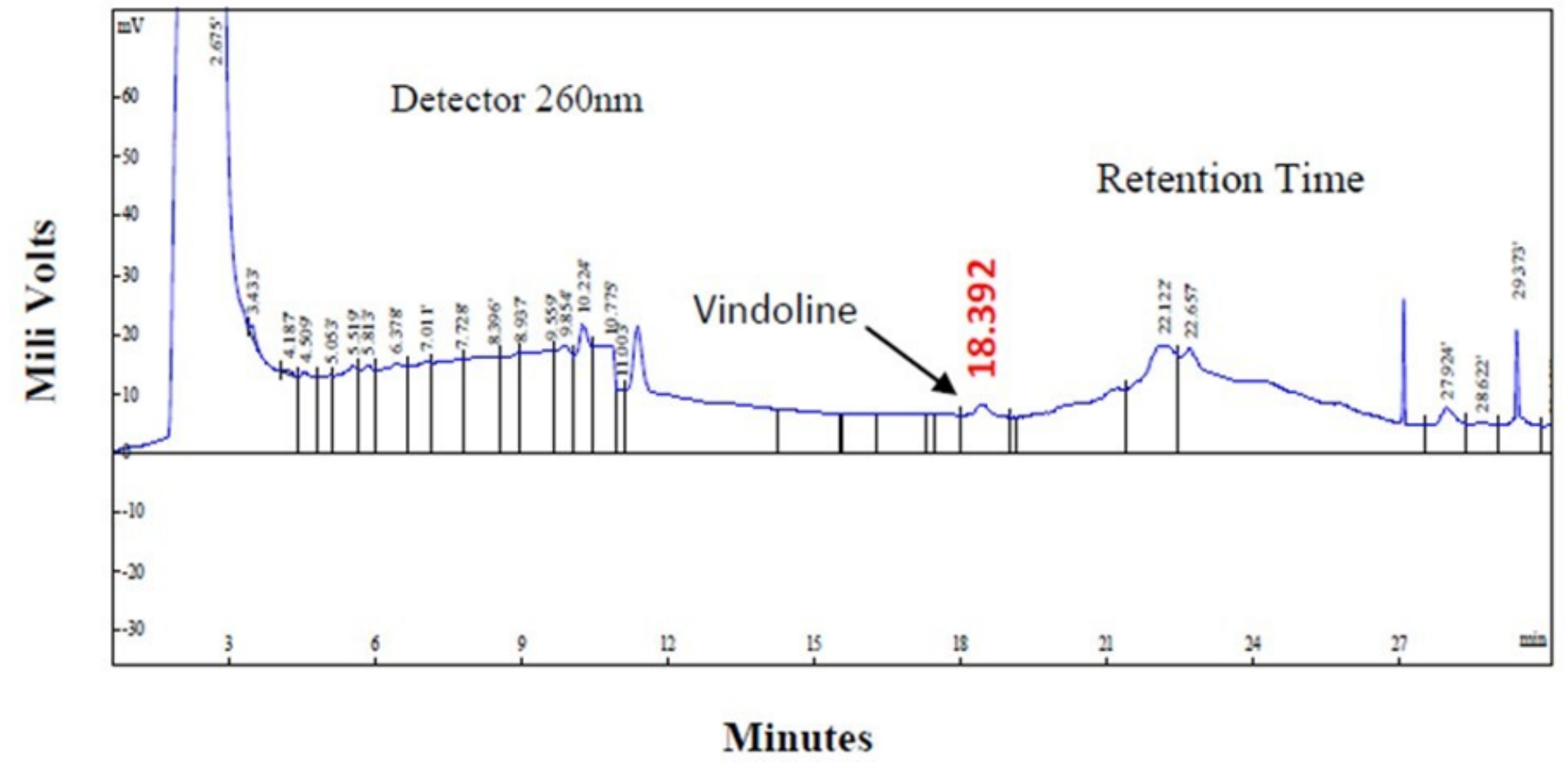

Figure 2

HPLC graph for Vindoline in fungal extract [RT=18.392]

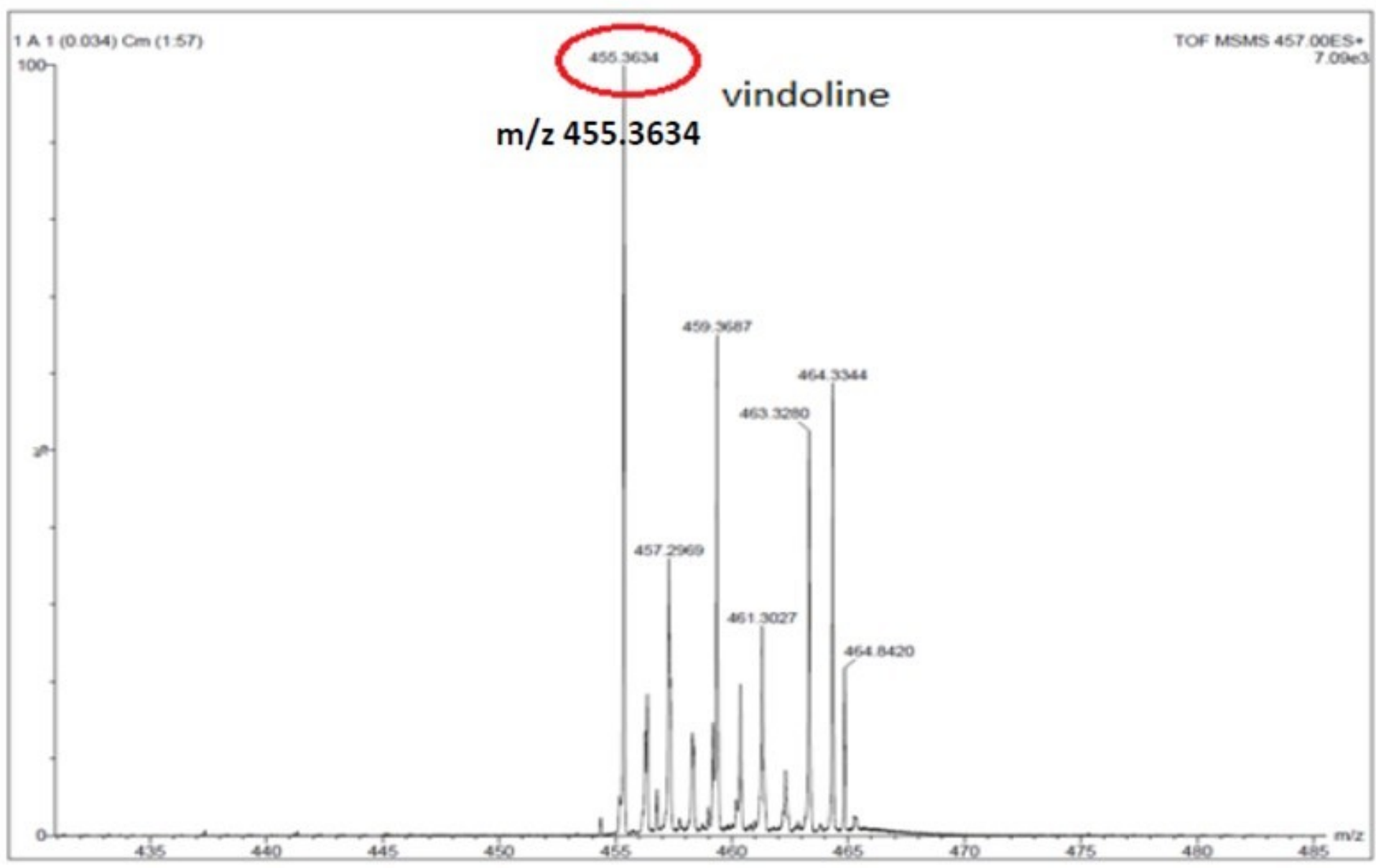

Figure 3 


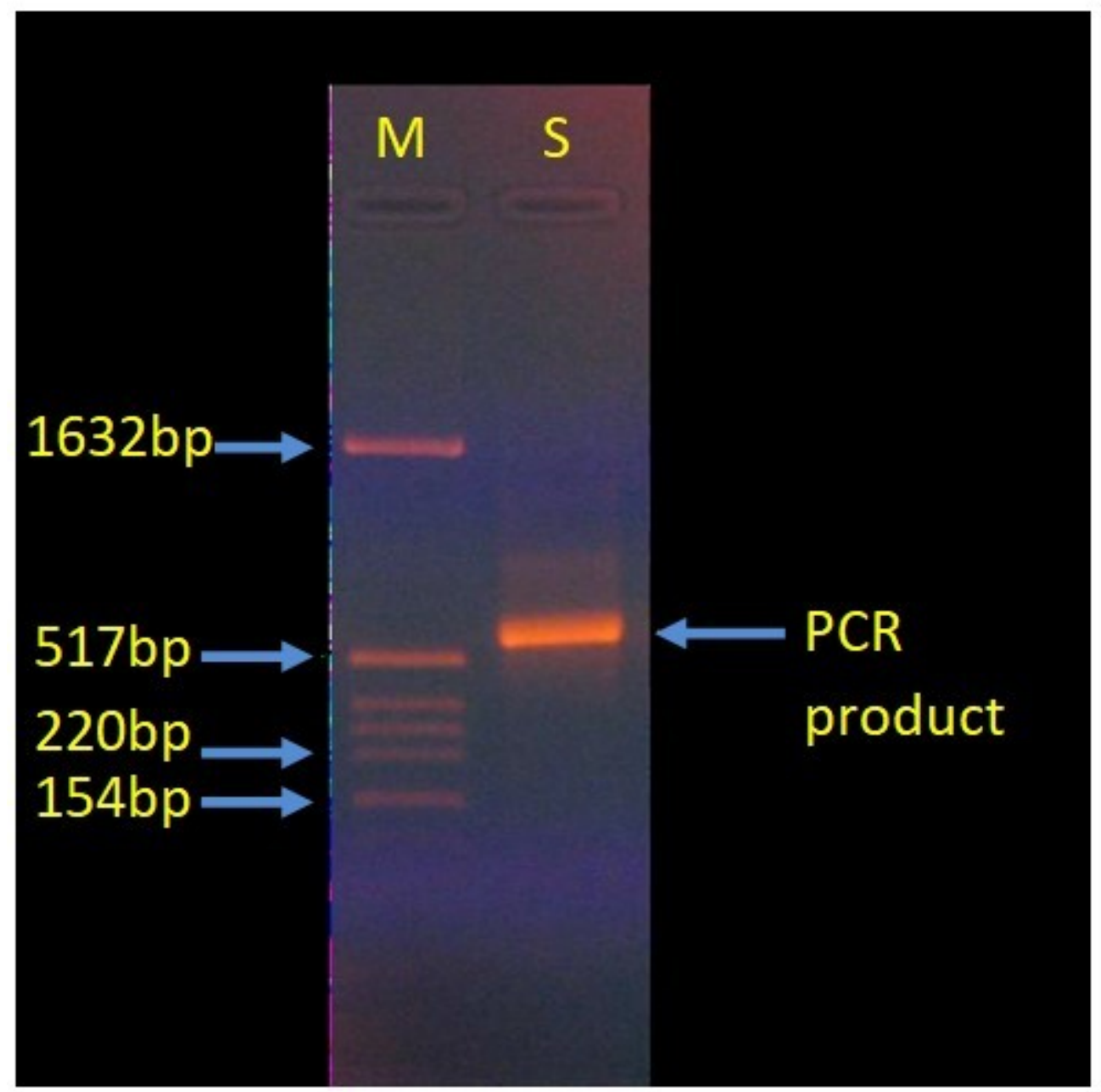

\section{Figure 4}

PCR amplification of ITS region of rRNA gene [1\% Agarose gel electrophoresis showing PCR product of 600bp], (M- Molecular size marker; S- Sample) 


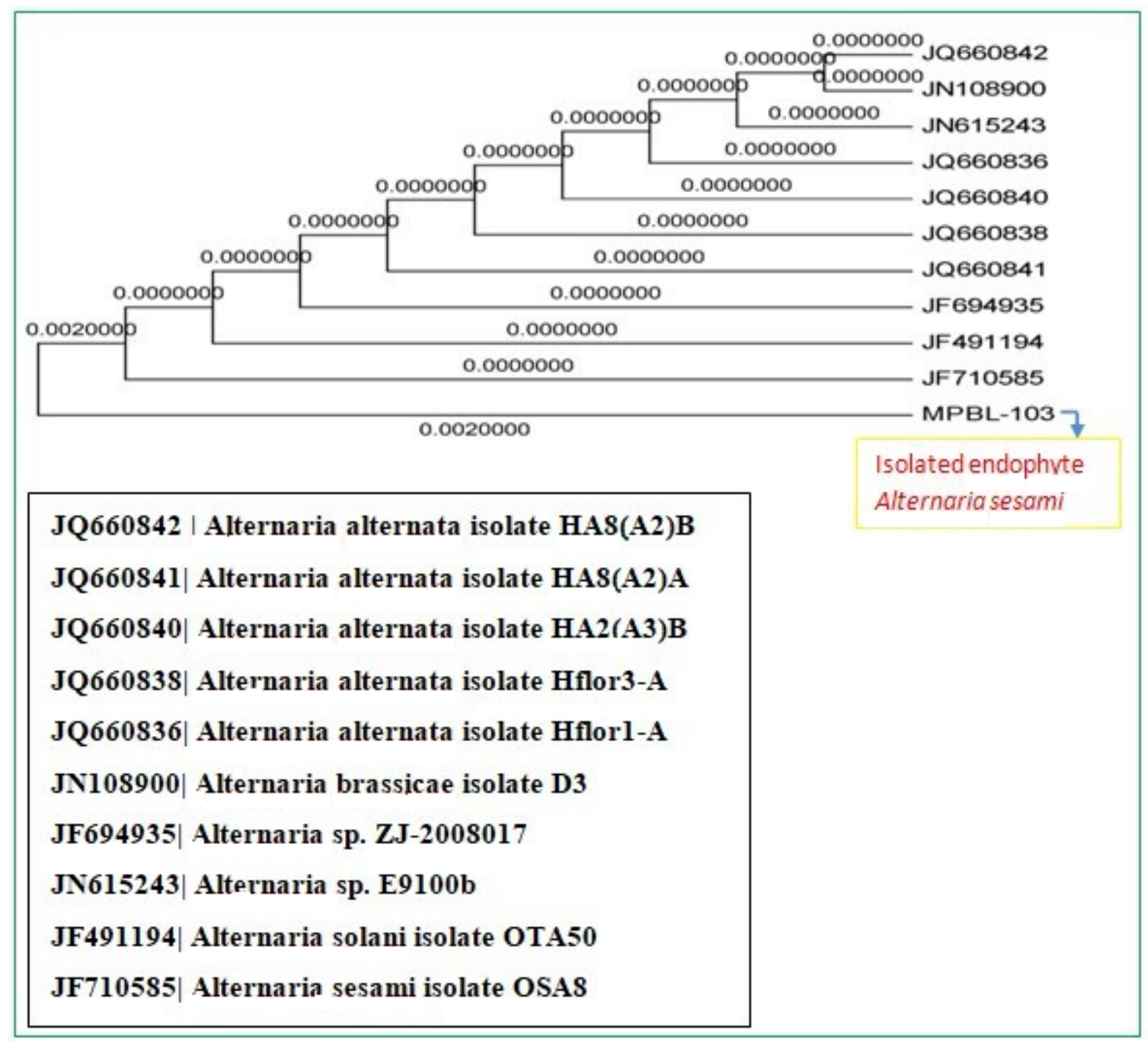

Figure 5

Phylogenetic tree of the isolated fungal endophyte Alternaria sesami 

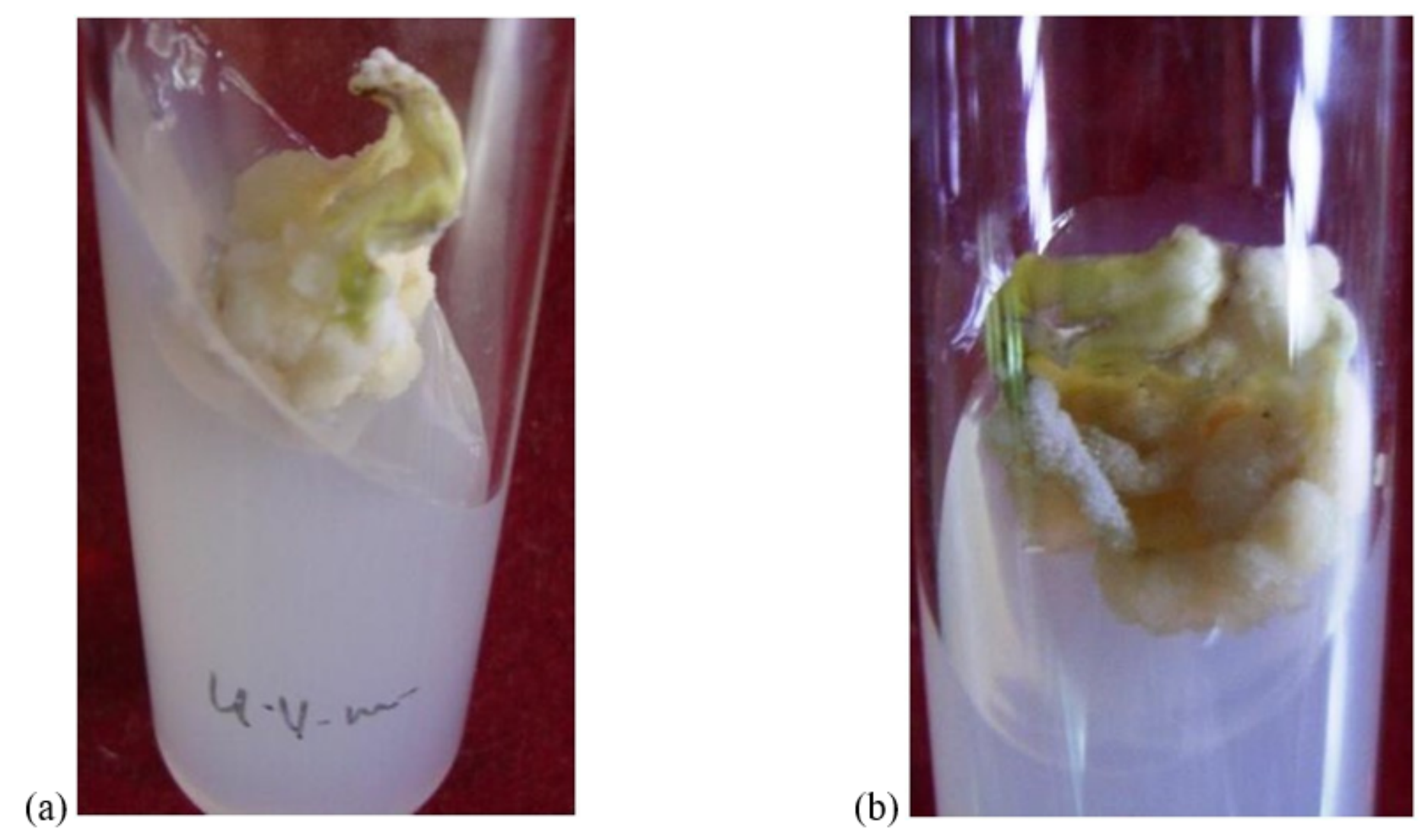

\section{Figure 6}

Callus initiation in different hormone combination observed after 15 days of innoculation: (a) 7th hormone combination [2,4-D + IAA + 6-BA]; (b) 10th hormone combination[2,4-D + IAA + Kinetin + 6-BA] 

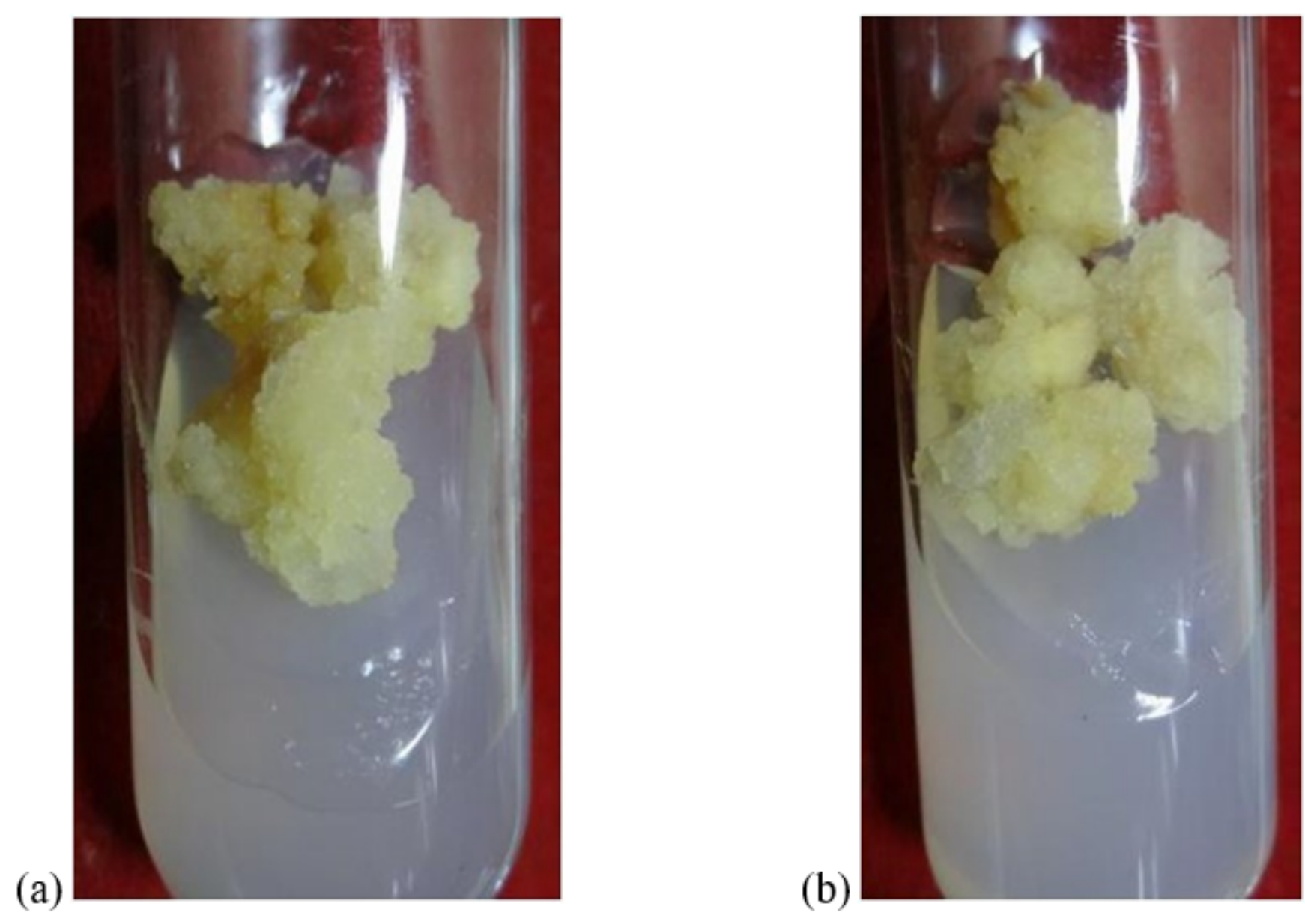

\section{Figure 7}

Effect of hormone concentration on callus observed after 30 days: (a) 7th hormone combination at 1ppm concentration; (b) 10th hormone combination at 1ppm concentration

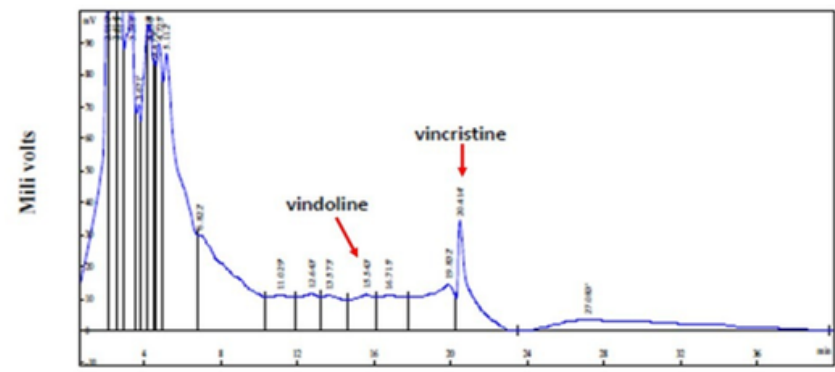

(a)

Minute:

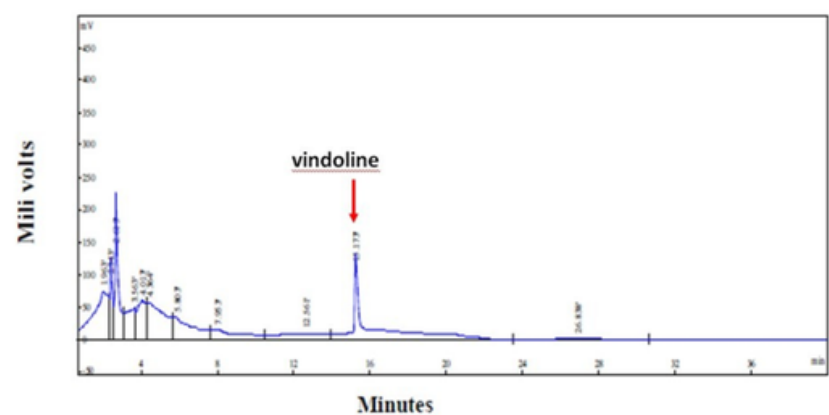

(c)

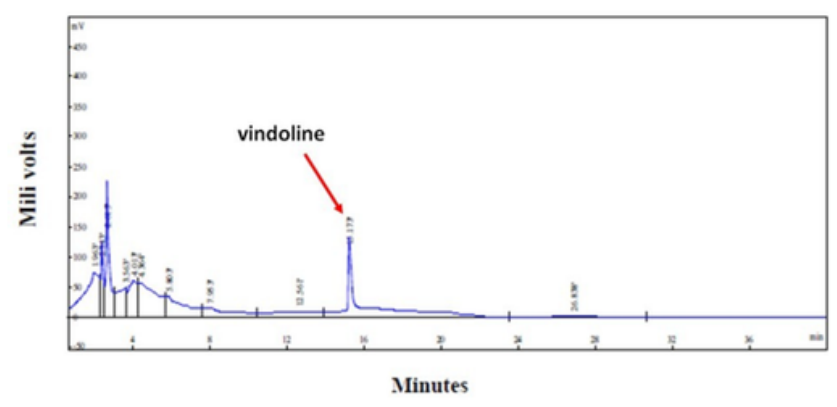

(d)

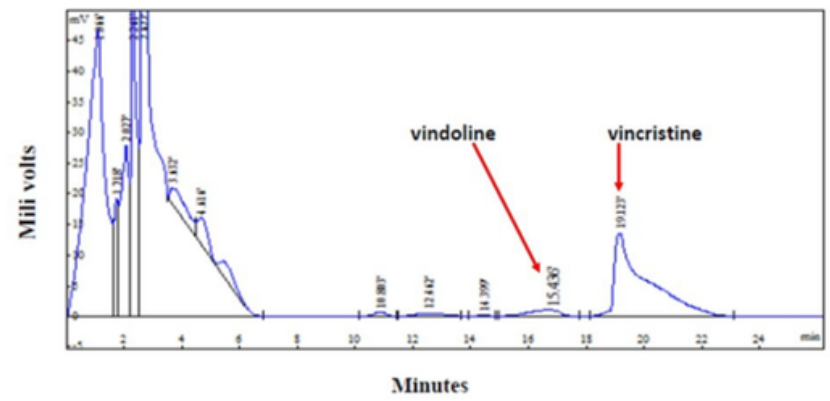


Figure 8

(a) HPLC Chromatogram of untreated 7th hormone combination callus; (b) HPLC Chromatogram of callus treated with methanol extract $(25 \mu \mathrm{l} / \mathrm{g})$ in 7 th hormone combination; (c) HPLC Chromatogram of callus treated with methanol extract $(25 \mu \mathrm{l} / \mathrm{g}$ ) in 10th hormone combination; (d) HPLC Chromatogram of callus treated with methanol extract $(50 \mu \mathrm{l} / \mathrm{g})$ in 10 th hormone combination

\section{Supplementary Files}

This is a list of supplementary files associated with this preprint. Click to download.

- S1.docx 